\title{
Southern Ocean mass variation studies using GRACE and satellite altimetry
}

\author{
Chung-Yen Kuo ${ }^{1}$, C. K. Shum² ${ }^{2}$ Jun-yi Guo ${ }^{2}$, Yuchan $\mathrm{Yi}^{2}$, Alexander Braun ${ }^{3}$, Ichiro Fukumori ${ }^{4}$ \\ Koji Matsumoto ${ }^{5}$, Tadahiro Sato ${ }^{6}$, and Kazuo Shibuya ${ }^{7}$ \\ ${ }^{1}$ Department of Geomatics, National Cheng-Kung University, Taiwan, R.O.C. \\ ${ }^{2}$ Geodetic Science, School of Earth Sciences, The Ohio State University, Columbus, Ohio, USA \\ ${ }^{3}$ Department of Geomatics Engineering, University of Calgary, Calgary, Canada \\ ${ }^{4}$ Jet Propulsion Laboratory, California Institute of Technology, Pasadena, California, USA \\ ${ }^{5}$ National Astronomical Observatory, Mizusawa, Japan \\ ${ }^{6}$ Research Center for Prediction of Earthquakes and Volcanic Eruptions, Tohoku University, Japan \\ ${ }^{7}$ National Institute of Polar Studies, Tokyo, Japan
}

(Received July 23, 2007; Revised November 13, 2007; Accepted December 17, 2007; Online published May 16, 2008)

\begin{abstract}
The Southern Ocean is a major link between the world oceans via complicated processes associated with the melting and accumulation of the vast Antarctic ice sheets and the surrounding sea ice. The Southern Ocean sea level is poorly observed except from recent near-polar orbiting space geodetic satellites. In this study, the Southern Ocean mass variations at the seasonal scale are compared using three independent data sets: (1) the Gravity Recovery And Climate Recovery Experiment (GRACE) observed ocean bottom pressure (OBP), (2) steric-corrected satellite altimetry (ENVISAT) and, (3) the Estimating the Circulation and Climate of the Ocean (ECCO) model OBP data. The height difference between sea level derived from altimetry and steric sea level contains the vertical displacement of the Earth surface due to elastic loading. Here we provide a formulation of this loading term which has not been considered previously in other studies and demonstrate that it is not negligible, especially for regional studies. In this study, we first conduct a global comparison using steric-corrected JASON-1 altimetry with GRACE to validate our technique and to compare with recent studies. The global ocean mass variation comparison shows excellent agreement with high correlation $(\sim 0.81)$ and with discrepancies at 3-5 mm RMS. However, the discrepancies in the Southern Ocean are much larger at 12-17 mm RMS. The mis-modeling of geocenter variations and the second degree zonal harmonic $\left(J_{2}\right)$ degrade the accuracy of GRACE-derived mass variations, and the choice of ocean temperature data sets and neglecting the loading correction on altimetry affect the OBP comparisons between GRACE and altimetry. This study indicates that the satellite observations (GRACE and ENVISAT) are capable of providing an improved constraint of oceanic mass variations in the Southern Ocean.
\end{abstract}

Key words: Southern Ocean, GRACE, altimetry.

\section{Introduction}

Complicated processes of the Antarctic ice sheet, the ambient sea ice, and the surrounding oceans link the Southern Ocean with the world oceans. Growth and melting of sea ice affect the Southern Ocean circulation and are regarded as an important forcing mechanism for the dense water formation that contributes to deep ocean circulation (Aoki, 2002). The high-latitude ocean is strongly stratified by the warmth of its surface water (Sigman et al., 2004). The circulation in the Southern Ocean is dominated by the zonal Antarctic Circumpolar Current (ACC), which is primarily wind-forced and is the only current that connects the Pacific, Indian, and Atlantic Oceans. The ACC isolates the Antarctic continent from warmer water equatorward to maintain a lower temperature around the continent (Orsi et al., 1995). Understanding the role of the Southern Ocean circulation in climate change, its interactions with ice and atmosphere, and the potential quantifi-

Copyright (c) The Society of Geomagnetism and Earth, Planetary and Space Sciences (SGEPSS); The Seismological Society of Japan; The Volcanological Society of Japan; The Geodetic Society of Japan; The Japanese Society for Planetary Sciences; TERRAPUB. cation of natural and anthropogenic climate-forcing mechanisms require long-term observations and improvement in modeling. While the warming of subsurface layers of the Southern Ocean since 1950 (Gille, 2002) appears to have been confirmed by satellite altimetry, at least for the past decade (Cabanes et al., 2001), the responsible forcing mechanisms remain speculative. In situ hydrographic data are extremely sparse, and accurate satellite altimetry, such as TOPEX/POSEIDON and JASON-1, are limited by their coverage to regions equator-ward of $\pm 66^{\circ}$ latitude. However, current and future high-latitude ocean-observing space geodetic sensors exist, including satellite altimetry such as GFO $\left( \pm 72^{\circ}\right)$, ERS- 2 or ENVISAT $\left( \pm 81.5^{\circ}\right)$, and CryoSat- 2 $\left( \pm 88^{\circ}\right)$ as well as spaceborne gravimetry (GRACE, $\left.\pm 89^{\circ}\right)$. These sensors provide an opportunity to study the ocean dynamics of the Southern Ocean, including processes driven by climate change.

Measuring and understanding the static and time-varying gravity fields and their relationship to climate-change signals are among the scientific objectives of the NASA/GFZ Gravity Recovery And Climate Experiment (GRACE) satellite mission (Tapley et al., 2004a). The two GRACE 
co-orbiting satellites are in a near-circular orbit with a mean altitude of $500 \mathrm{~km}$ and a mean inclination of $89^{\circ}$, which enables near-polar coverage.

The GRACE mission has been successfully providing monthly observations of the Earth's gravity field since its launch in 2002 (Tapley et al., 2004a). These observations are represented in spherical harmonic coefficients complete to degree 120, and they have been demonstrated to represent the Earth's water mass redistribution at a spatial resolution of $400 \mathrm{~km}$ (Tapley et al., 2004b). Wahr et al. (2004) showed that the current GRACE gravity field solutions can be used to recover monthly changes in water storage, both on land and in ocean, with an accuracy of about $1.5 \mathrm{~cm}$ of water thickness when smoothed over a $1000-\mathrm{km}$ spatial scale. The annual amplitude of large hydrological basins, including the Amazon, could be determined to accuracies of $1.0-1.5 \mathrm{~cm}$. Chambers et al. (2004) showed that the annual frequency $(8.6 \pm 1.1 \mathrm{~mm}$ in amplitude and $265^{\circ} \pm 8^{\circ}$ in phase) of the averaged GRACE ocean mass variations (within $\pm 66^{\circ}$ latitude) agree well with the sea level variations computed using 11 years of averaged TOPEX/POSEIDON altimetry after correcting for the steric (thermosteric and halosteric) component using in situ measurements. Chambers (2006) followed up an updated study using improved GRACE data product and modeling. Chen et al. (2005) indicated that the non-steric global mean sea level observed from altimetry, GRACE, and geophysical models during 2002-2004 agree well. Song and Zlotnicki (2005) found a good agreement between GRACE ocean mass variations and the non-Boussinesq ocean model for the annual component by subtracting the tropical Pacific Ocean bottom pressure signals from the sub-Arctic signals, attributing the observed GRACE variations primarily to the 2002-2003 El Nino Southern Oscillation. Zlotnicki et al. (2007) compared GRACE ocean mass variations with two ocean circulation models near the polar oceans in the ACC region and found the discrepancies between GRACE and the ocean models to be $17 \mathrm{~mm}$ RMS, which is much larger than the global comparisons (e.g., Chambers, 2006). The oceanic mass variation signal is larger in the polar region than in the equatorial region; however, both signals are much smaller than hydrological or other land/ice-originated signals. For example, the annual amplitude of global ocean mass variations is $<1 \mathrm{~cm}$ (Chen et al., 2005), while the annual amplitude of water storage in Amazon basin is $>30 \mathrm{~cm}$ (Han et al., 2005a). This aspect is also indicated by Andersen and Hinderer (2005), who estimated GRACE errors of $5 \mathrm{~mm}$ RMS near the poles to $13 \mathrm{~mm}$ around the equator. In addition to estimating mass variations, Garcia et al. (2007) and Lombard et al. (2007) combined GRACE with satellite altimetry to estimate steric sea level with an annual amplitude of about $6 \mathrm{~mm}$.

In this study, we compared the GRACE observed mass variations in the global ocean and the Southern Ocean using two independent data sets: the steric-corrected sea level from satellite altimetry (JASON-1, $\pm 66^{\circ}$, and high-latitude observing ENVISAT, $\pm 81.5^{\circ}$ ) and ocean bottom pressure (OBP) from the NASA/JPL's Estimating the Circulation and Climate of the Ocean (ECCO) model (Fukumori et al., 1999). The global comparison aims to validate various im- proved correction models, including the geocenter (degree 1 coefficients which are not observable by GRACE) correction and the displacement correction due to elastic loading effect, which has not been considered before, and to compare the results with those of other studies (e.g. Chambers et $a l ., 2004)$. The regional comparison can be used to explore the potential of using data from these sensors and the ocean model for improved constraints of steric and ocean mass variation signals in the sparsely observed Southern Ocean.

\section{Data Processing}

\subsection{Ocean mass variations from satellite altimetry}

Satellite altimetry, such as JASON-1 and ENVISAT, observes geocentric sea surface heights, while in situ hydrographic data of temperature and salinity (e.g., expendable bathythermograph or XBT data) can be used to estimate steric sea level heights (Garcia et al., 2007). One method to infer ocean mass variations is to subtract the computed steric anomalies from the observed sea level variations derived from satellite altimetry (e.g., Chambers et al., 2004; Chambers, 2006; Kuo et al., 2004b; Chen et al., 2005). Two data sets, the World Ocean Atlas 2001 (WOA01) (Stephens et al., 2002) and monthly gridded data from Ishii et al. (2006) (hereafter, Ishii06), are used to derive steric sea level variation in this study. Although WOA01 and Ishii06 data cover the global oceans over a 50-year time span, the available in situ measurements over the Southern Ocean are very sparse (Stephens et al., 2002). The temperature and salinity data of the WOA01 objectively analyzed fields are available each month on a $1^{\circ} \times 1^{\circ}$ grid. Data represent the mean gridded climatology averaged for all years at an annual temporal scale. On the other hand, the Ishii06 monthly mean temperature fields available on a $1^{\circ} \times 1^{\circ}$-grid and covering the topmost layer to $700 \mathrm{~m}$ depth from 1945 to 2005 represent an actual monthly thermosteric sea level data set. We employ the equation of the state taking into account nonlinear mixing effects of temperature and salinity (Gille, 2004) to compute monthly climatological steric sea level anomalies relative to the annual mean field. First, steric sea level anomalies are calculated by integrating from the sea surface to a depth of $1500 \mathrm{~m}$ using WOA01. Figure 1(a) and (b) shows the annual mean steric sea level computed for 0-1500 m over the global oceans and over the Southern Ocean, respectively, demonstrating that the density of seawater in the equatorial ocean is relatively lower than in the higher latitude oceans. The differences of annual phases and amplitudes in the global oceans derived from Ishii06 and WOA01 are $9.3^{\circ}$ and $2.2 \mathrm{~mm}$, respectively, while the differences in the Southern Ocean are $4.5^{\circ}$ and $2.0 \mathrm{~mm}$, respectively (Fig. 1(c)). Therefore, the choice of the steric sea level model could affect the estimate of ocean mass variation derived from satellite altimetry.

In this study, JASON-1 and ENVISAT radar altimeter data, which are provided by the Physical Oceanography Distributed Active Archive Center (PODAAC) and European Space Agency (ESA), respectively, are used in the form of sea level anomalies with all standard corrections applied, including the dry and wet troposphere, ionosphere, solid Earth and ocean tides, pole tide, and inverted barometric (IB) corrections. Table 1 shows a comparison of annual 

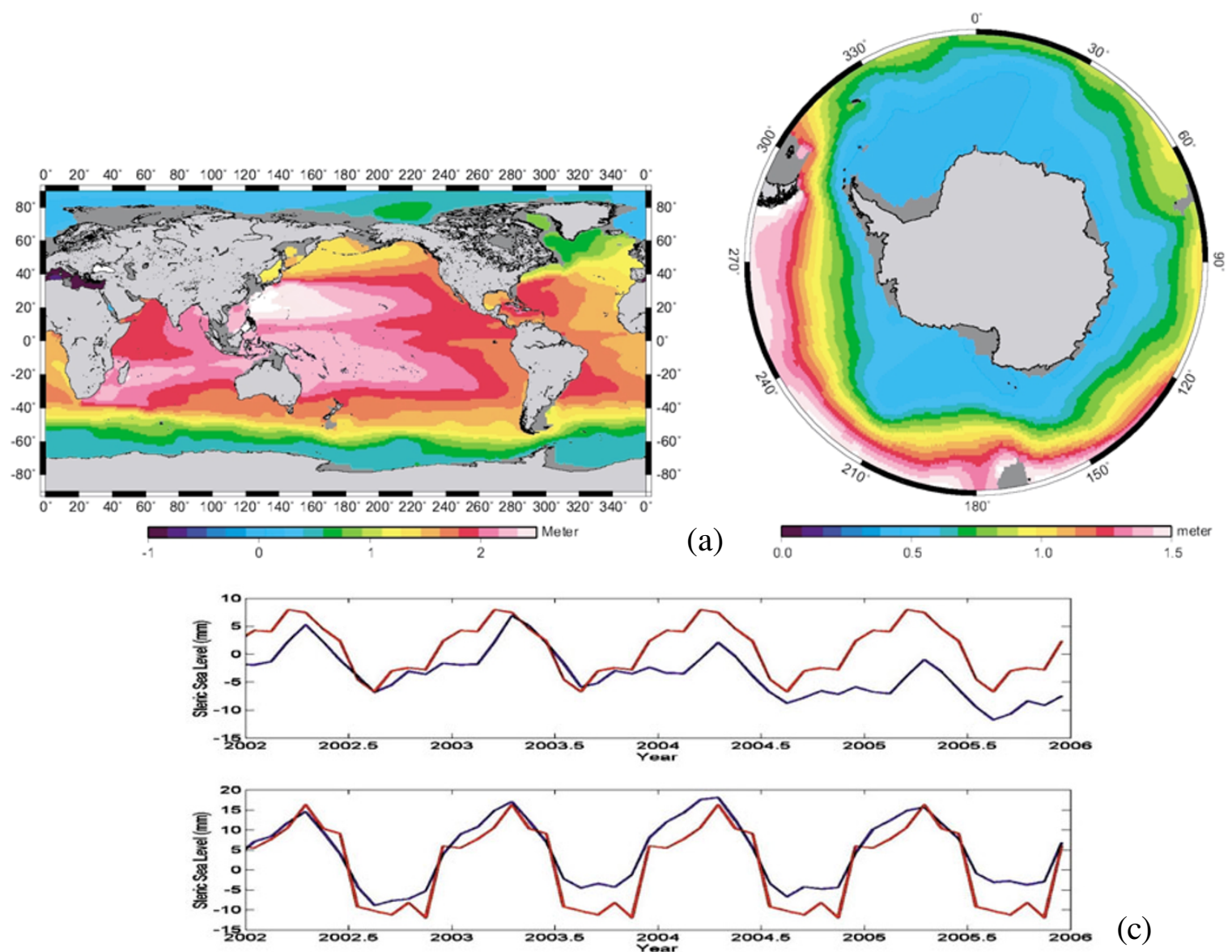

(c)

Fig. 1. Annual mean steric anomalies computed for $0-1500 \mathrm{~m}$ using WOA01 (Fig. 1(a)). Southern Ocean projection covering latitude $-50^{\circ}$ to $-90^{\circ}$ is shown on right (Fig. 1(b)). Top panel of Fig. 1(c) presents two time series of globally averaged steric (thermosteric) sea level derived from WOA01 (red curve) and Ishii06 (blue curve). Bottom panel of Fig. 1(c) is similar to the top one except for the averaged area (latitude: $50^{\circ} \mathrm{S} \sim 90^{\circ} \mathrm{S}$ ).

Table 1. Comparison of estimated annual amplitude and phase of the global ocean mass variations derived from JASON-1 in combination with WOA01 and Ishii06, respectively, without the displacement correction due to loading effects (January 2002 to September 2005).

\begin{tabular}{|l|c|c|}
\hline & $\begin{array}{c}\text { Amplitude } \\
(\mathrm{mm})\end{array}$ & $\begin{array}{c}\text { Phase }\left(^{\circ}\right) \\
\text { (from January 1) }\end{array}$ \\
\hline Steric(WOA01)-Corrected JASON-1 & $9.8 \pm 1.0$ & $267.0 \pm 5.6$ \\
\hline Steric(Ishii06)-Corrected JASON-1 & $8.2 \pm 0.9$ & $286.5 \pm 11.0$ \\
\hline
\end{tabular}

mass variations derived from JASON-1 altimetry covering the period from January 2002 to September 2005 combined with WOA01 and Ishii06. Applying different steric sea level data to derive ocean mass variations causes a significant discrepancy in the annual component (1.6-mm differences in amplitude and $19.5^{\circ}$ or about 20 days in phase). Therefore, the uncertainties of ocean temperature and salinity data could be an error source in estimating oceanic mass variations. In addition, the uncertainty of the annual phase determined using Ishii06 happens to be larger than that using WOA01, as the mean fields of WOA01 are climatological or averaged seasonal signals over several decades (top of Fig. 1(c)). In order to understand the error caused by different time spans, we also estimated the annual amplitudes and phases of global mass variations derived from JASON1 altimetry and Ishii06 for the following time spans, Jan
2002-Dec 2002, Jan 2002-Dec 2003, Jan 2002-Dec 2004, and Jan 2002-Dec 2005. The discrepancies in estimated annual amplitudes go up to $1.9 \mathrm{~mm}$ and to as large as $6.4^{\circ}$ in the estimated phases.

The height difference between sea level derived from altimetry and steric sea level contains the vertical displacement of the Earth's surface due to elastic loading effect. For the purpose of computing the net water mass change, this displacement should be modeled, and it may not be negligible, especially in regional studies. Here we formulated and applied this correction, which has not been considered in earlier studies. The following equation is used to compute the loading displacement, $u_{r}$ (Guo et al., 2004):

$$
\begin{aligned}
u_{r}(\theta, \lambda)= & a \sum_{n=0}^{\infty} \sum_{m=0}^{n} \frac{h_{n}}{\left(k_{n}+1\right)} \times\left(\bar{C}_{n m} \cos (m \lambda)+\bar{S}_{n m} \sin (m \lambda)\right) \\
& \times \bar{P}_{n m}(\cos \theta)
\end{aligned}
$$

where $\bar{C}_{n m}$ and $\bar{S}_{n m}$ are the geopotential spherical harmonic coefficients; $a$ is the radius of Earth; $n$ is degree and $m$ is order; $\theta$ is co-latitude and $\lambda$ is longitude; $k_{n}$ and $h_{n}$ are the load Love numbers of degree $n$ that describe the Earth's elastic deformation; $\bar{P}_{n m}$ is the fully normalized associated Legendre function. Numerical Love numbers are adopted from Guo et al. (2004). Spherical harmonic coefficients of 48 monthly GRACE gravity fields (see also 
Table 2. Comparison of estimated annual amplitude and phase of the global ocean mass variations derived from steric(Ishii06)-corrected JASON-1 (April 2002 to September 2005) and of the Southern Ocean mass from steric(Ishii06)-corrected ENVISAT (October 2002 to August 2005) with or without the displacement correction due to elastic loading effects.

\begin{tabular}{|l|c|c|}
\hline & $\begin{array}{c}\text { Amplitude } \\
(\mathrm{mm})\end{array}$ & $\begin{array}{c}\text { Phase }\left(^{\circ}\right) \\
\text { (from January 1) }\end{array}$ \\
\hline $\begin{array}{l}\text { Steric(Ishii06)-Corrected JASON-1 } \\
\text { w/o loading correction }\end{array}$ & $8.5 \pm 0.9$ & $282.2 \pm 7.3$ \\
\hline $\begin{array}{l}\text { Steric(Ishii06)-Corrected JASON-1 } \\
\text { with loading correction }\end{array}$ & $9.0 \pm 0.9$ & $280.6 \pm 6.5$ \\
\hline $\begin{array}{l}\text { Steric(Ishii06)-Corrected ENVISAT } \\
\text { w/o loading correction }\end{array}$ & $10.7 \pm 2.6$ & $340.1 \pm 13.4$ \\
\hline $\begin{array}{l}\text { Steric(Ishii06)-Corrected ENVISAT } \\
\text { with loading correction }\end{array}$ & $11.7 \pm 2.7$ & $340.0 \pm 12.6$ \\
\hline
\end{tabular}

Section 2.2) were employed to compute the displacement of the loading effects, which were then applied to the ocean mass variations inferred from satellite altimetry and steric sea level. This correction resulted in a change in (global annual) amplitude of $0.5 \mathrm{~mm}$ and in phase of $1.6^{\circ}$ and reduced the formal uncertainty of phase by $0.8^{\circ}$ (Table 2 ). In the Southern Ocean, the amplitude change due to this correction is $1 \mathrm{~mm}$, twice as large as that for the global case (Table 2), but the phase difference is not significant, presumably because of the large uncertainty. In addition, the amplitude of the annual displacement of the loading effect can reach $3 \mathrm{~mm}$ in the Pacific Ocean and 3-4 mm in the Arctic Ocean. We thus conclude that this elastic loading term should be modeled when estimating ocean mass variations using steric-corrected satellite altimetry.

\subsection{GRACE ocean mass observations}

In this study, 48 monthly gravity field solutions (April/May 2002-June 2006) from the initial release of GRACE data products (L2 Release 1 or RL01 data product with a constrained solution which improved the lowdegree harmonic estimates including $J_{2}$ ) provided by CSR were used. The Release 4 (RL04) data product only became available later. We evaluated the RL04 data set and concluded that the use of the earlier release of GRACE data (RL01) will not change the results of this study (also see Section 3). Here, the average of 48 GRACE monthly gravity fields from the RL01 data product is chosen as a reference field, which is subtracted from all the gravity fields to obtain 48 monthly temporal gravity solutions. The majority of the GRACE analyses so far have primarily used the isotropic or Gaussian filtering of a given radius, which assumes that the signal-to-noise level decreases with increasing degree (Wahr et al., 2004; Chambers et al., 2004; Andersen and Hinderer, 2005; Tapley et al., 2004a; Zlotnicki et al., 2007; Song and Zlotnicki, 2005) to reduce noise involved in the coefficients. Davis et al. (2004) used an F-test to select GRACE coefficients and achieved a significant reduction in the annual signal variance in the data. In this study, we adopt the non-isotropic filtering of the GRACE L2 data products with a $500-\mathrm{km}$ (latitude) by $800-\mathrm{km}$ (longitude) filter (Shum et al., 2004; Han et al., 2005b), which is an extension of the filter based on the selection of the co-
Table 3. Comparison of estimated annual amplitude and phase of the global ocean mass variations derived from 48 months of GRACE solutions with different geocenter corrections from J. Ries (Personal communication) and Chen et al. (1999) (April 2002 to July 2006).

\begin{tabular}{|l|c|c|}
\hline & $\begin{array}{c}\text { Amplitude } \\
(\mathrm{mm})\end{array}$ & $\begin{array}{c}\text { Phase }\left(^{\circ}\right) \\
\text { (from January 1) }\end{array}$ \\
\hline $\begin{array}{l}\text { GRACE with geocenter correction } \\
\text { (from J. Ries) }\end{array}$ & $9.0 \pm 0.5$ & $244.6 \pm 3.3$ \\
\hline $\begin{array}{l}\text { GRACE with geocenter correction } \\
\text { (from Chen } \text { et al. } \text { (1999)) }\end{array}$ & $8.1 \pm 0.5$ & $252.1 \pm 3.8$ \\
\hline
\end{tabular}

efficients that are highly correlated with signals computed from geophysical (hydrological and ocean) models (Kuo et al., 2004a). Water thickness variations, $\Delta h$, can be calculated according to Wahr et al. (1998) using spherical harmonic coefficients:

$$
\begin{aligned}
\Delta h(\theta, \lambda)= & \frac{a \sigma_{E}}{3 \sigma_{w}} \sum_{n=0}^{\infty} \sum_{m=0}^{n} \bar{P}_{n m}(\cos \theta) \frac{(2 n+1)}{\left(k_{n}+1\right)} \\
& \times\left(\bar{C}_{n m} \cos (m \lambda)+\bar{S}_{n m} \sin (m \lambda)\right),
\end{aligned}
$$

where $\sigma_{w}$ is the density of water $\left(1000 \mathrm{~kg} \mathrm{~m}^{-3}\right)$, and $\sigma_{E}$ is the average density of the Earth $\left(5517 \mathrm{~kg} \mathrm{~m}^{-3}\right)$. There is an indication of large scatter of GRACE estimated $J_{2}$ coefficients as compared to satellite laser ranging (SLR) solutions (Ries, 2004). Instead of substituting the $J_{2}$ coefficients using the SLR solutions, here we also compute $\Delta h$ with or without including $J_{2}$ (Wahr et al., 2004) to validate its effect on estimating GRACE-observed ocean mass variations. Ries (2004) indicated a good agreement between GRACE and SLR solutions for $C_{21}, C_{22}, S_{22}, C_{30}$, and $C_{31}$, but a worse agreement for $S_{21}$. The secular rate of low-degree zonal harmonics ( $n=2$ to 5 ) of GRACE was not removed since here we assess only seasonal signals, and the effects are small —on the order of $<10^{-11} / \mathrm{yr}$. The combined effect of the atmosphere-ocean de-aliasing (AOD) model, which is to estimate the non-IB barotropic signals, is used as a background forcing model to reduce high-frequency barotropic signals from the GRACE gravity fields over the oceans. In order to compare GRACE data with the inverted barometer-corrected altimetry ocean mass variations, the AOD model has to be added back to the GRACE data (Chambers et al., 2004). However, the global average of the AOD model is near zero because the model conserves mass. Even for regional studies (e.g., in the Mediterranean Sea), the averaged AOD signal is small with a root-mean-square (RMS) of $6 \mathrm{~mm}$ (Fenoglio-Marc et al., 2006). In the Southern Ocean, the RMS of the AOD model is $3.6 \mathrm{~mm}$. In this study, the AOD model is added back to the GRACE data before comparisons are made in the Southern Ocean to ensure consistency. GRACE is insensitive to geocenter variations, represented by degree $1(n=1)$ coefficients of the geopotential spherical harmonics, and thus the geocenter correction needs to be considered for comparisons with satellite altimetry observed oceanic mass variations (e.g., Chambers, 2006). In this study, ocean pole tide (Wahr, 1985) and geocenter corrections (two solutions, one using Lageos-1 and Lageos-2 SLR (J. Ries, personal communications) and the other from Chen et al. (1999)) were applied to the GRACE 
Table 4. Comparison of estimated annual amplitude and phase of the global ocean mass variations from steric-corrected JASON-1, non-isotropic filtered GRACE, and other studies using GRACE (Chamber et al., 2004) and using hydrological models (Cazenave et al., 2000) (April 2002 to September 2005).

\begin{tabular}{|c|c|c|}
\hline & $\begin{array}{l}\text { Amplitude } \\
\text { (mm) }\end{array}$ & $\begin{array}{c}\text { Phase }\left(^{\circ}\right) \\
\text { (from January 1) }\end{array}$ \\
\hline Steric(Ishii06)-Corrected JASON-1 & $9.0 \pm 0.9$ & $280.6 \pm 6.5$ \\
\hline Steric(WOA01)-Corrected JASON-1 & $10.6 \pm 1.0$ & $263.4 \pm 6.0$ \\
\hline GRACE (with $J_{2}$, with Chen et al. (1999) geocenter correction) & $8.1 \pm 0.6$ & $250.8 \pm 4.4$ \\
\hline GRACE (w/o $J_{2}$, with Chen et al. (1999) geocenter correction) & $6.7 \pm 0.2$ & $256.1 \pm 1.5$ \\
\hline GRACE (with $J_{2}$, with geocenter correction from J. Ries) & $9.0 \pm 0.6$ & $243.4 \pm 3.8$ \\
\hline GRACE (w/o $J_{2}$, with geocenter correction from J. Ries) & $7.6 \pm 0.2$ & $246.7 \pm 1.3$ \\
\hline ECCO (without Greatbatch correction) & $5.6 \pm 0.5$ & $281.3 \pm 4.8$ \\
\hline GRACE, Chambers et al. (2004) & $8.6 \pm 1.1$ & $265 \pm 8$ \\
\hline Cazenave et al. (2000) & 9.0 & 250 \\
\hline
\end{tabular}

data. The corrections are discussed in detail in Chambers et al. (2004), Chambers (2006), Fenoglio-Marc et al. (2006), and Chen et al. (2005).

Geocenter corrections inferred from two different sources show a noticeable difference in estimated amplitude and phase of $0.9 \mathrm{~mm}$ and $7.5^{\circ}$, respectively (Table 3 ). Therefore, the uncertainty of the geocenter correction could be an error source when processing the GRACE solution to compute change in water thickness and has to be considered.

\subsection{ECCO ocean model}

Ocean data assimilation provides a means to dynamically extrapolate observations into coherent descriptions of the ocean, including properties that are not directly measured. One such estimate is the "Estimating the Circulation and Climate of the Ocean" (ECCO) model of NASA/JPL (see Fukumori et al., 1999 for an early version of this model; see also http://www.ecco-group.org) based on the Massachusetts Institute of Technology general circulation model (MITgcm) (Marshall et al., 1997). In this study, we use the run designated kf066b of the ECCO-JPL model, which assimilates altimetric sea level data (TOPEX/POSEIDON and Jason-1) and temperature profiles (WOCE hydrography, XBTs, and profiling floats) using a partitioned Kalman filter (Fukumori, 2002). The ECCO model is a nonlinear primitive equation model using the Boussinesq approximation with a vertical resolution of 46 layers from the sea surface to a depth of $6000 \mathrm{~m}$, a spatial resolution of $1^{\circ}$, and a near-global model domain from $72.5^{\circ} \mathrm{S}$ to $72.5^{\circ} \mathrm{N}$ latitude. The readers are referred to Lee and Fukumori (2003) for additional information about this model and its configuration.

On one hand, the model by itself is volume-conserving and does not conserve mass. A common correction for ocean bottom pressure for volume conserving models is to remove variations of the total mass in the ocean (i.e., global spatial mean ocean bottom pressure variations) from the estimates, thus rendering the pressure estimates relative to the unknown global mean mass of the ocean (Greatbatch, 1994). On the other hand, the filtering assimilation of TOPEX altimetry data in the ECCO model potentially alters the model's volume and mass by inverting the model-data relationship in accordance to estimated uncertainties of the model and data. In this study, we will employ ECCO-JPL's kf066b estimates with and without such global mass correction (the "Greatbatch correction") to examine the model's fidelity in relation to space geodetic and steric-corrected sea level estimates of ocean bottom pressure variations.

\section{Results and Discussion}

Table 4 shows the global annual signals (amplitudes and phases, phases in degrees from January $1^{\text {st }}$ ) estimated using GRACE-observed ocean mass variations, the stericcorrected JASON-1 sea level variations, and results from other studies. Excluding $J_{2}$ changes the amplitude by $1.4 \mathrm{~mm}$ and the phase by $3.3^{\circ}$ (or $5.3^{\circ}$ depending on the different geocenter corrections applied). Chambers et al. (2004) (isotropic filtered GRACE ocean mass variations) and this study both show a good agreement with a 0.5$\mathrm{mm}$ in amplitude difference and $14.8^{\circ}(\sim 15$ days) in phase difference, which are smaller than twice the formal uncertainties. The comparison of GRACE data smoothed using a non-isotropic filtering radius (Han et al., 2005b) of $500 \times 800 \mathrm{~km}$ in latitude and longitude, respectively, and steric-corrected altimeter ocean mass variations shows small differences of $0.9-2.5 \mathrm{~mm}$ in amplitude and $13^{\circ}-30^{\circ}$ in phase (Table 4).

Figure 2 shows the comparison of the global $\left( \pm 66^{\circ}\right)$ ocean mass variations derived from the GRACE, stericcorrected JASON-1 altimetry, and the ECCO (kf066b run) model ocean bottom pressure without the Greatbatch correction during the 2002-2005. All three estimates of the global ocean mass variations show an excellent agreement, except that the ECCO model's estimate has a relatively smaller amplitude, while the Ishii06 steric-corrected JASON-1 altimetry (red curve) shows the largest amplitude. The similarities between the model and the two observation-based estimates suggest that the model assimilation may have simulated the global ocean mass variability well despite model limitations (volume conserving) and approximations in the assimilation (partitioned filter, etc). Matsumoto et al. (2006) also indicated the similar tendency of a smaller annual amplitude in the ECCO model using TOPEX, JASON-1, ECCO and in situ OBP observations in a regional comparison study near Sanriku, Japan, in the northwest Pacific. The reason for the discrepancy is at present unknown. Table 5 (left panel) shows that the RMS difference and the correlation coefficient between the 


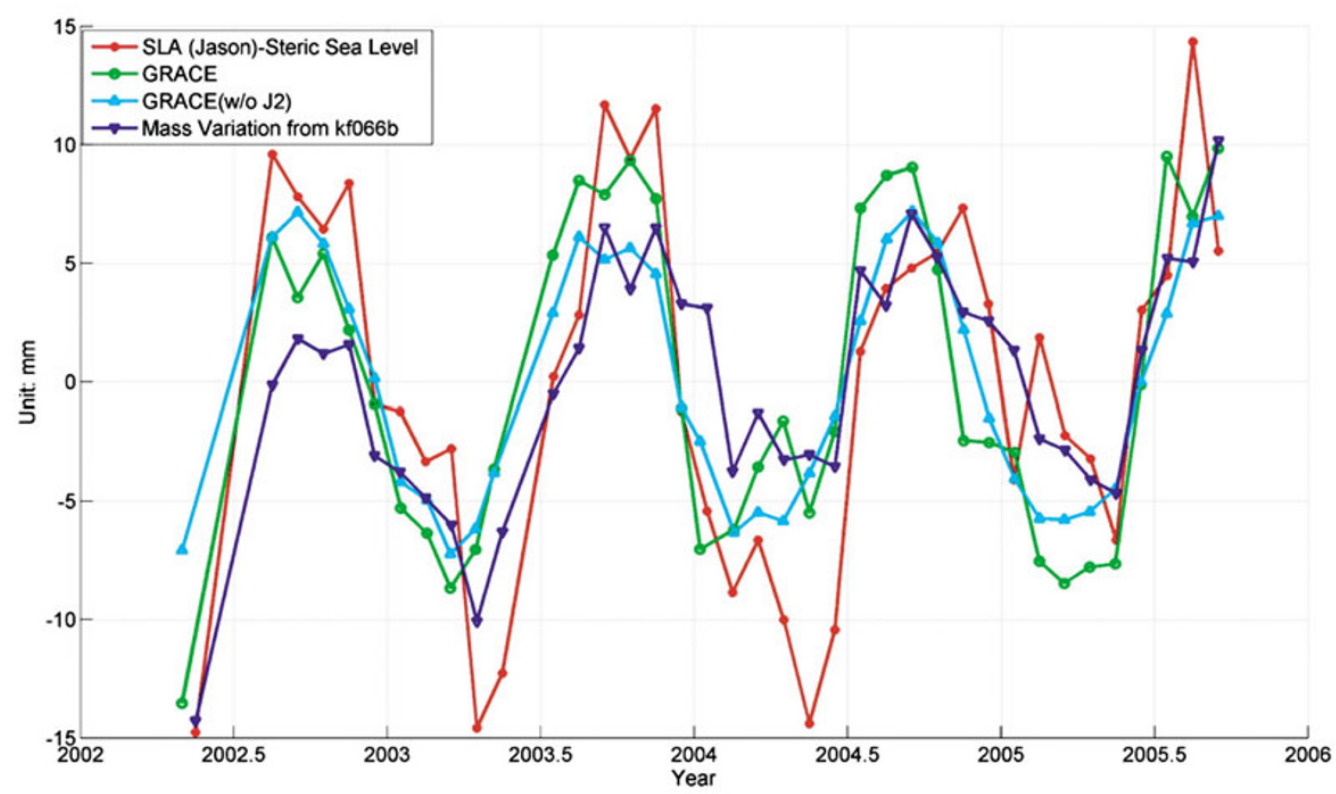

Fig. 2. Comparison of the global $\left( \pm 66^{\circ}\right)$ ocean mass variations derived from GRACE (with and without $J_{2}$; Chen $e t$ al. (1999) geocenter correction), steric(Ishii06)-corrected JASON-1 altimetry, and ECCO (without Greatbatch mass conservation correction) ocean bottom pressure for the time period 2002-2005.

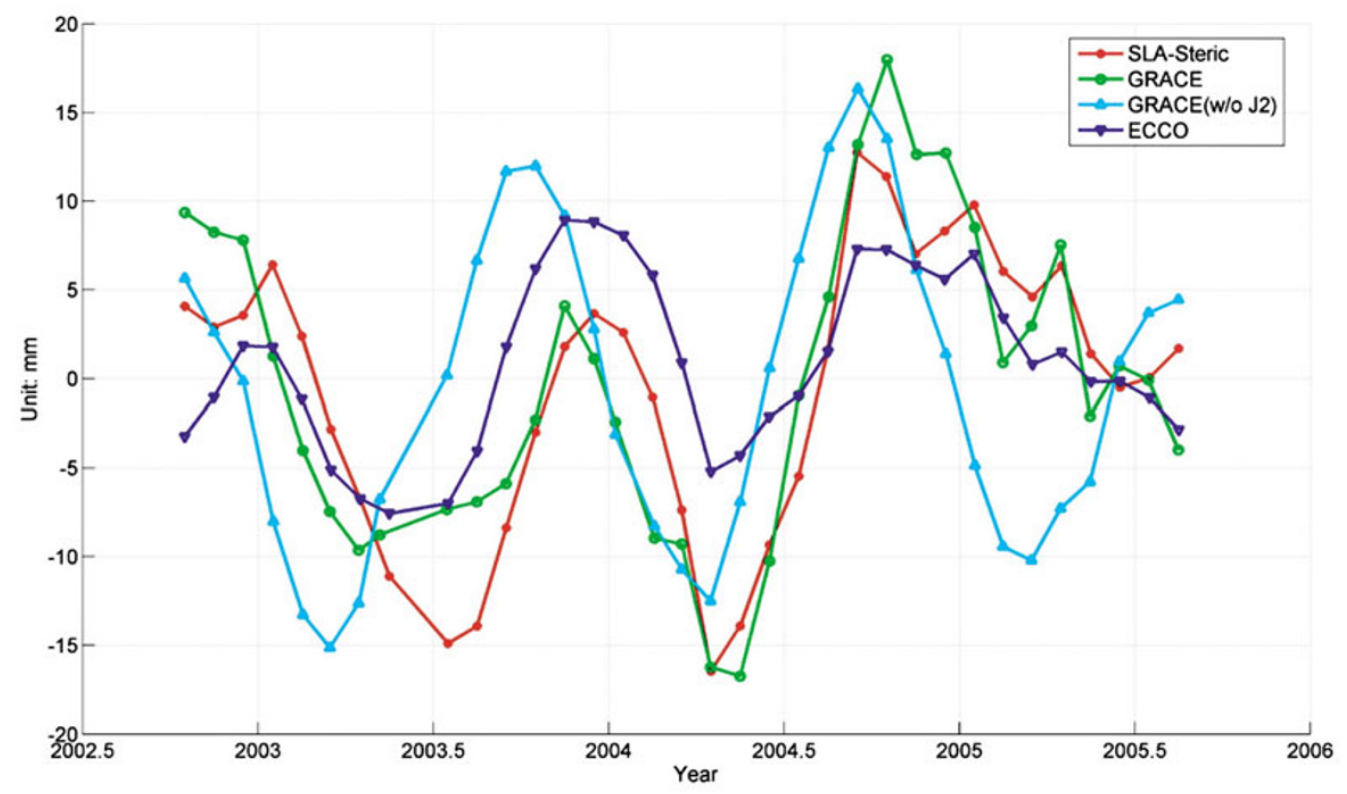

Fig. 3. Comparison of the Southern Ocean mass variations (latitude: $50^{\circ} \mathrm{S} \sim 75^{\circ} \mathrm{S}$; longitude: $0^{\circ} \mathrm{E} \sim 360^{\circ} \mathrm{E}$ ) derived from GRACE (with and without $J_{2}$; Chen et al. (1999) geocenter correction), steric(Ishii06)-corrected ENVISAT altimetry, and ECCO model (without Greatbatch correction) ocean bottom pressure.

GRACE and steric-corrected JASON-1 (global oceans) are around $5 \mathrm{~mm}$ and 0.8 , respectively, while the difference and correlation coefficient between GRACE and ECCO models are around $3.5 \mathrm{~mm}$ and 0.8 , respectively, indicating excellent agreement. The definition of variance/correlation coefficient, $C C$, is as follows:

$C C=\left(\int_{t 1}^{t 2} y_{1 t} y_{2 t} d t\right) /\left[\left(\int_{t 1}^{t 2} y_{1 t}^{2} d t\right)^{1 / 2}\left(\int_{t 1}^{t 2} y_{2 t}^{2} d t\right)^{1 / 2}\right]$

where $y_{1}$ and $y_{2}$ are time series, and time span between $t_{1}$ and $t_{2}$ is used.

Next, we focused on our regional study region, the Southern Ocean, where ocean mass variations are much larger than those near the equatorial or the mid-latitude areas (Zlotnicki et al., 2007; Song and Zlotnicki, 2005). We used the GRACE product of 48 monthly solutions from April/May 2002 to June 2006 (with respect to the average of 48 monthly gravity fields) for the Southern Ocean study. Figure 3 shows the comparison of monthly time series (smoothed with a 5-month window moving average $)$ in the Southern Ocean between GRACE $(500 \times 800 \mathrm{~km}$ 
Table 5. Comparison of GRACE (geocenter correction (Chen et al., 1999)), ECCO model (with or without Greatbatch mass conservation correction), and steric(Ishii)-corrected altimetry (JASON-1 and ENVISAT) in the global ocean (April 2002 to September 2005) and the Southern Ocean (October 2002 to August 2005). For altimetry and GRACE comparisons, square brackets indicate the statistics for the case when loading corrections are not applied to the steric-corrected altimetry. For the GRACE and ECCO comparisons in the Southern Ocean, the second rows (with parenthesis) indicate the statistics for ECCO model with Greatbatch correction.

\begin{tabular}{|c|c|c|c|}
\hline \multicolumn{2}{|c|}{$\begin{array}{c}\text { Global }\left( \pm 66^{\circ}\right) \\
\text { RMS }(\mathrm{mm}) / \text { Correlation }\end{array}$} & \multicolumn{2}{|c|}{$\begin{array}{c}\text { Southern Ocean }\left(-50^{\circ} \text { to }-75^{\circ}\right) \\
\text { RMS }(\mathrm{mm}) / \text { Correlation }\end{array}$} \\
\hline 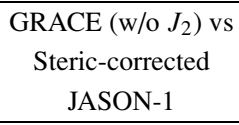 & $\begin{array}{c}4.7 / 0.81 \\
{[4.6 / 0.79]}\end{array}$ & 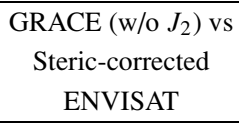 & $\begin{array}{c}15.7 / 0.28 \\
{[15.4 / 0.28]}\end{array}$ \\
\hline $\begin{array}{l}\left.\text { GRACE (w/o } J_{2}\right) \\
\text { vs ECCO }\end{array}$ & $3.3 / 0.79$ & $\begin{array}{l}\text { GRACE }\left(\text { w/o } J_{2}\right) \\
\text { vs ECCO }\end{array}$ & $\begin{array}{c}12.2 / 0.45 \\
(14.7 / 0.04)\end{array}$ \\
\hline $\begin{array}{c}\text { GRACE vs } \\
\text { Steric-corrected } \\
\text { JASON-1 }\end{array}$ & $\begin{array}{c}5.3 / 0.74 \\
{[5.3 / 0.71]}\end{array}$ & $\begin{array}{c}\text { GRACE vs } \\
\text { Steric-corrected } \\
\text { ENVISAT }\end{array}$ & $\begin{array}{c}15.6 / 0.52 \\
{[16.9 / 0.42]}\end{array}$ \\
\hline $\begin{array}{l}\text { GRACE } \\
\text { vs ECCO }\end{array}$ & $3.9 / 0.81$ & $\begin{array}{l}\text { GRACE } \\
\text { vs ECCO }\end{array}$ & $\begin{array}{c}17.1 / 0.32 \\
(17.3 / 0.26)\end{array}$ \\
\hline
\end{tabular}

Table 6. Comparison of estimated annual amplitude and phase of the Southern Ocean mass variations (latitude: $-50^{\circ}$ to $-90^{\circ}$, longitude: $0^{\circ}$ to $\left.360^{\circ}\right)$ derived from steric-corrected ENVISAT, GRACE and ECCO model with and without Greatbatch correction (October 2002 to August 2005 ).

\begin{tabular}{|l|c|c|}
\hline & $\begin{array}{c}\text { Amplitude } \\
(\mathrm{mm})\end{array}$ & $\begin{array}{c}\text { Phase }\left(^{\circ} \text { ) }\right. \\
\text { (from January 1) }\end{array}$ \\
\hline Steric(Ishii06)-Corrected ENVISAT & $11.7 \pm 2.7$ & $340.0 \pm 12.6$ \\
\hline GRACE (with $J_{2}$, Chen et al. $(1999)$ geocenter correction) & $12.9 \pm 4.1$ & $308.1 \pm 18.1$ \\
\hline GRACE (w/o $J_{2}$, Chen et al. (1999) geocenter correction) & $17.6 \pm 1.2$ & $260.5 \pm 4.2$ \\
\hline ECCO (without Greatbatch correction) & $8.4 \pm 1.6$ & $324.8 \pm 10.6$ \\
\hline ECCO (with Greatbatch correction) & $6.0 \pm 1.4$ & $363.4 \pm 13.3$ \\
\hline
\end{tabular}

non-isotropic filtered, with or without including $J_{2}$ ), stericcorrected ENVISAT, and the ECCO model (without the Greatbatch correction). The agreement is significantly worse than the global comparison, and the annual signal in the Southern Ocean is not as apparent as the globally averaged signal. The three data sets have noticeably different amplitudes but agree reasonably well in seasonal highs and lows, except that for the case of GRACE without the inclusion of $J_{2}$, which has a distinct phase shift of $>50^{\circ}$, indicating the importance of accurate $J_{2}$ modeling for GRACE ocean mass variation estimates.

Table 5 (right panel, Southern Ocean comparison) shows that the RMS differences between GRACE, steric-corrected ENVISAT altimetry, and the ECCO model are as large as $17.3 \mathrm{~mm}$ and that the correlation coefficients are less than 0.52. It should be noted that the available thermosteric anomalies of both Ishii06 and WOA01 are largely missing or very sparse in the Southern Ocean. Table 5 also shows that for both the global and Southern Ocean comparisons, neglecting the loading correction in the steric-corrected altimetry slightly increases RMS differences and reduces the correlation when compared with GRACE (including $J_{2}$ ) ocean mass variations. It is interesting to note that in the Southern Ocean comparison (Table 5, right panel), the ECCO model corrected for global mass conservation (Greatbatch correction) shows a slightly worse RMS and decreased correlation when compared with GRACE than that without the global mass removal. Table 6 shows that the annual amplitudes and phases derived from different data sets in the Southern Ocean have much larger discrepancies than those in the global comparison, especially for the estimates from the ECCO model (with or without the Greatbatch correction). Additionally, phase uncertainties are relatively large. This is similar to the result of the global comparison that the ECCO model shows a smaller annual amplitude. At present, it is difficult to assess which data set, GRACE or the steric-corrected ENVISAT altimetry, is more accurate in the Southern Ocean. We have also processed the more recently released GRACE L2 Release 4 (RL04) data product from CSR. We used this data product to estimate the annual mass variation signal for the global ocean and the Southern Ocean as a validation to decide whether we should use the RL04 data in favor of the RL01 data used in this study. The procedure we used is the same as Section 2.2 except that ocean pole tide correction was not applied since the model has already been included in the RL04 data product solutions. The estimated annual amplitude and phase of global ocean mass variations are $8.1 \pm 0.5 \mathrm{~mm}$ and $256.0^{\circ} \pm 3.4^{\circ}$, respectively, after applying the (Chen et al., 1999) geocenter correction. In the Southern Ocean, the estimated annual amplitude and phase are $9.3 \pm 3.8 \mathrm{~mm}$ and $309.4^{\circ} \pm 23.3^{\circ}$, respectively. In both cases, the estimated annual amplitude differences from using the GRACE RL01 and RL04 data products are much less that the formal uncertainties (Tables 5 and 6). Therefore, we conclude that the use of the more recent released GRACE data product (RL04) would not change the conclusions in this study.

\section{Conclusions}

We conducted a comparison of the GRACE observations of global and Southern Ocean mass variations (April/May 2002-June 2006) with the steric-corrected 
JASON-1 and ENVISAT altimetry using the steric sea levels from WOA01 climatology and Ishii06 models, and with the ocean bottom pressure estimates of the ECCO ocean data assimilation model. The annual variations show excellent agreement between the estimates for global mass variations, but with significantly larger discrepancies for mass variations of the Southern Ocean, implying that GRACE and altimetry data could potentially provide an improved constraint on steric sea level and ocean mass variations in the Southern Ocean. The causes of the discrepancies in the observations can be attributed to the errors in the steric sea level corrections due primarily to the lack of data in the Southern Ocean, the data gaps of the ENVISAT altimetry due to sea ice cover, and the error due to the continental hydrologic leakage in the GRACE data. In addition, the geocenter correction is an error source when computing ocean mass variation from GRACE and should be taken into consideration. The effect from non-mass conservation of the standard equilibrium ocean pole tide correction used in satellite altimeter data is also an error source for global mass variation study (Chen et al., 2005). The origin of ocean model errors is less certain. However, the similarities between the model estimate and the observations, in particular those of global mass, are intriguing and illustrate the fidelity of the model and assimilation in simulating ocean bottom pressure in spite of their various approximations. Finally, height difference between sea level derived from altimetry and steric sea level contains the vertical displacement of the Earth's surface due to elastic loading. This loading term has not been considered in earlier studies and is not negligible especially for regional studies.

Acknowledgments. This work is supported by grants from NASA (NNG04GF01G, NAG5-12585 and NNG04GN19G). Additional computing resources were provided by the Ohio Supercomputer Center. The first author is partially supported by a grant from the National Science Council (NSC96-2221-E-006-148). We thank two anonymous reviewers and the editor (J. W. Kim) for their constructive comments, which have improved the paper. We acknowledge Victor Zlotnicki for providing useful comments and John Ries for providing the LAGEOS SLR geocenter solution time series. Data sets used in this research are provided by the University of Texas Center for Space Research (GRACE), and by JPL PO-DACC (GRACE and JASON-1), and ESA/ESRIN (ENVISAT).

\section{References}

Andersen, O. and J. Hinderer, Global inter-annual gravity changes from GRACE: Early results, Geophys. Res. Lett., 32, L01402, doi:10. 1029/2004GL020948, 2005.

Aoki, S., Coherent sea level response to the Antarctic Oscillation, Geophys. Res. Lett., 29(20), 1950, doi:10.1029/2002GL015733, 2002.

Cabanes, C., A. Cazenave, and C. Le Provost, Sea level changes from TOPEX-POSEIDON altimetry for 1993-1999 and possible warming of the Southern Oceans, Geophys. Res. Lett., 28(1), 9-12, 2000GL011962, 2001.

Cazenave, A., F. Remy, K. Dominh, and H. Douville, Global ocean mass variation, continental hydrology and the mass balance of Antarctica ice sheet at seasonal time scale, Geophys. Res. Lett., 27, 3755-3758, 2000.

Chambers, D., Observing seasonal steric sea level variations with GRACE and satellite altimetry, J. Geophys. Res., 111, C03010, doi:10. 1029/2005JC002914, 2006.

Chambers, D., J. Wahr, and R. Nerem, Preliminary observations of global ocean mass variations with GRACE, Geophys. Res. Lett., 31, L13310, doi:10.1029/2004GL020461, 2004.

Chen, J. L., C. R. Wilson, R. J. Eanes, and R. S. Nerem, Geophysical inter- pretation of observed geocenter variations, J. Geophys. Res., 104(B2), 2683-2690, 1999.

Chen, J. L., C. R. Wilson, B. D. Tapley, J. S. Famiglietti, and M. Rodell, Seasonal global mean sea level change from satellite altimeter, GRACE, and geophysical models, J. Geod., 79, 532-539, doi:10.1007/s00190005-0005-9, 2005.

Davis, J., P. Elosequi, J. Mitrovica, and M. Tamisiea, Climate-driven deformation of the solid Earth from GRACE and GPS, Geophys. Res. Lett., 31, L24605, doi:10.1029/2004GL021435, 2004.

Fenoglio-Marc, L., J. Kusche, and M. Becker, Mass variation in the Mediterranean Sea from GRACE and its validation by altimetry, steric and hydrologic fields, Geophys. Res. Lett., 33, L19606, doi:10. 1029/2006GL026851, 2006.

Fukumori, I., A partitioned Kalman filter and smoother, Monthly Weather Rev., 130, 1370-1383, 2002

Fukumori, I., R. Raghunath, L. Fu, and Y. Chao, Assimilation of TOPEX/POSIEDON altimeter data into a global ocean circulation model: How good are the results?, J. Geophys. Res., 104(C11), 25,647$25,665,1999$.

Garcia, D., G. Ramillien, A. Lombard, and A. Cazenave, Steric sealevel variations inferred from combined Topex/Poseidon altimetry and GRACE gravimetry, Pure Appl. Geophys., 164, 721-731, 2007.

Gille, S., Warming of the Southern Ocean, Science, 295, 1275-1277, 2002.

Gille, S., How nonlinearities in the equation of state of seawater can confound estimates of steric sea level change, J. Geophys. Res., 109, C03005, doi:10.1029/2003JC002012, 2004.

Greatbatch, R. J., A note on the representation of steric sea level in models that conserve volume rather than mass, J. Geophys. Res., 99, 1276712771, 1994.

Guo, J. Y., Y. B. Li, Y. Huang, H. T. Deng, S. Q. Xu, and J. S. Ning, Green's function of the deformation of the Earth as a result of atmospheric loading, Geophys. J. Int., 159, 53-68, doi:10.1111/j.1365246X.2004.02410.x, 2004.

Han, S. C., C. K. Shum, and A. Braun, High-resolution continental water storage recovery from low-low satellite-to-satellite tracking, J. Geodyn., 39, 11-28, 2005a.

Han, S. C., C. K. Shum, C. Jekeli, C. Y. Kuo, C. Wilson, and K. W. Seo, Non-isotropic filtering of GRACE temporal gravity for geophysical signal enhancements, Geophys. J. Int., 163(1), 18-25, doi:10.1111/j.1365246X.2005.02756.x, 2005b.

Ishii, M., M. Kimoto, K. Sakamoto, and S. I. Iwasaki, Steric sea level changes estimated from historical ocean subsurface temperature and salinity analyses, J. Oceanogr., 62, 155-170, 2006.

Kuo, C., C. Shum, A. Braun, I. Fukumori, Z. Xing, and Y. Yi, Southern Ocean sea level variation studies using steric data, GRACE ocean mass variations and ocean modeling, Proc. Gravity, Geoid and Space Mission (Abstract), Porto, Portugal, August 30-September 3, 2004a.

Kuo, C. Y., A. Braun, S. C. Han, C. K. Shum, Y. Yi, K. Shibuya, K. Doi, and K. Matsumoto, Oceanic mass constraint studies in East Antarctica Ocean, Proc. $15^{\text {th }}$ International Symposium on Earth Tides (Abstract), Ottawa, Canada, August 2-6, 2004 b.

Lee, T. and I. Fukumori, Interannual to decadal variation of tropicalsubtropical exchange in the Pacific Ocean: boundary versus interior pycnocline transports, J. Climate, 16, 4022-4042, 2003.

Lombard, A., D. Garcia, G. Ramillien, A. Cazenave, R. Biancale, J. M. Lemoine, F. Flechtner, R. Schmidt, and M. Ishii, Estimation of steric sea level variations from combined GRACE and Jason-1 data, Earth Planet. Sci. Lett., 254, 194-202, doi:10.1016/j.epsl.2006.11.035, 2007.

Marshall, J. C., A. Adcroft, C. Hill, L. Perelman, and C. Heisey, A finitevolume, incompressible Navier Stokes model for studies of the ocean on parallel computers, J. Geophys. Res., 102, 5753-5766, 1997.

Matsumoto, K., T. Sato, H. Fujimoto, Y. Tamura, M. Nishino, R. Hino, T. Higashi, and T. Kanazawa, Ocean bottom pressure observation off Sanriku and comparison with ocean tide models, altimetry, and barotropic signals from ocean models, Geophys. Res. Lett., 33, L16602, doi:10.1029/2006GL026706, 2006.

Orsi, A. H., T. Whitworth, and W. D. Nowling, On the meridional extent and fronts of the Antarctic Circumpolar Current, Deep Sea Res., Ser. I, 42, 641-673, 1995.

Ries, J., Low degree harmonics in GRACE monthly solutions, Joint CHAMP/GRACE Science Meeting, http://www.gfz-potsdam. de/pb1/JCG, Potsdam, Germany, July 5-8, 2004.

Shum, C., S. Han, C. Kuo, K. Seo, and C. Wilson, Assessment of GRACE time-variable gravity observables: A new filtering technique to enhance signal spatial resolutions, Eos Trans. AGU, 85(47), Fall Meet. Suppl., Abstract G31C-0814, San Francisco, December 13-17, 2004. 
Sigman, D., S. Jaccard, and G. Haug, Polar ocean stratification in a cold climate, Nature, 428, 59-63, 2004.

Song, Y. T. and V. Zlotnicki, Subarctic ocean-bottom-pressure oscillation and its link to the tropical Pacific ENSO oscillation, J. Climate, 2005 (in press).

Stephens, J., T. Antonov, T. P. Boyer et al., World Ocean Atlas 2001, vol. 1, Temperatures, NOAA Atlas NESDIS 49, edited by S. Levitus, 176 pp., U.S. Govt. Print. Office, Washington, D.C., 2002.

Tapley, B. D., S. Bettadpur, M. Watkins, and C. Reigber, The Gravity Recovery and Climate Experiment; Mission Overview and Early Results, Geophys. Res. Lett., 31(9), 10.1029/2004GL019920, 2004a.

Tapley, B. D., S. Bettadpur, J. Ries, P. Thompson, and M. Watkins, GRACE Measurements of Mass Variability in the Earth System, Science, 305, 503-505, 2004b.

Wahr, J., Deformation induced by polar motion, J. Geophys. Res., 90,
9363-9368, 1985.

Wahr, J., M. Molenaar, and F. Bryan, Time variability of the Earth's gravity field: Hydrological and oceanic effects and their possible detection using GRACE, J. Geophys. Res., 103(B12), 30,205-30,229, 1998.

Wahr, J., S. Swenson, V. Zlotnicki, and I. Velicogna, Time-variable gravity from GRACE: First results, Geophys. Res. Lett., 31, L11501, doi:10. 1029/2004GL019779, 2004.

Zlotnicki, V., J. Wahr, I. Fukumori, and Y. T. Song, Antarctic circumpolar current transport variability during 2003-05 from GRACE, J. Phys. Oceanogr., 37, 230-244, 2007.

C.-Y. Kuo (e-mail: kuo70@mail.ncku.edu.tw), C. K. Shum, J. Guo, Y. Yi, A. Braun, I. Fukumori, K. Matsumoto, T. Sato, and K. Shibuya 